\section{JIBM}

Journal of International Business and Management (JIBM) Journal Homepage: https://rpajournals.com/jibm

\title{
How Followers Contribute to Team Success, Leadership Transformation and Organizational Excellence
}

\author{
Audrey Ralon' \\ Jordan Rothenberg ${ }^{2}$ \\ Ghadeer Odeh* \\ Meghan Turney \\ Yingting $\mathrm{Wu}^{\mathrm{s}}$ \\ The George Washington University, USA ${ }^{123,45}$
}

\begin{abstract}
Followers have typically been overlooked compared to leaders in an organizational setting but are a huge component of team success. A coach would not get "100 career wins" without the hard work of the team members on the field playing the game. A performer would not have the prosperity of a sold-out tour without the dedication of his fans. Followers are present in every group setting and are integral to the success of the team. They also play a part beyond supporting and following the leader. Followers' engagement, relationships, and well-being directly affect the organization and leader. This paper will further explore the meaning of a follower and leader, examine the follower-leader interaction and its effectiveness in a team, and the overall value followers contribute to team success. In addition, this paper will reveal the critical success factors to maintain healthy follower-leader dynamics, it emphasizes the important role of practicing mindfulness, creating assertive communication and engagement channels, creating a motivating, and learning organizational culture, and boosting critical thinking and brainstorming activities to generate new pathways to boost organizational innovation. This case analysis will further help illustrate how the behaviors of the followers can shape leadership style and exhibit the importance of team recognition to create a healthy follower-leader relationship.

Keywords: Team leadership, Team dynamics, Followership qualities, Transformational leadership, Organization culture, Motivation, Organization change

*Corresponding author: Ghadeer Odeh; Email: ghadeerodeh@gwu.edu DOI: https://doi.org/10.37227/JIBM-2021-11-1476
\end{abstract}

\section{Introduction}

Leadership has been one of the most prominent research topics that took the attention of organizations emerging from the belief that leaders are capable of doing transformations due to the extraordinary abilities and traits they possess. However, the contemporary theory redefined the meaning of leadership considering the significance and contributions of the role to reach success. Levi (2017). To create effective followership, followers should embrace attributes such as motivation, assertiveness, critical thinking, and independence. The research revealed that taskoriented behaviors which are commonly used by followers can promote transactional leadership style 
in followers. (Niam, 2018). In addition, the leader-follower interaction should be based on trust, motivation, and positive engagement to create healthy work settings. The leader-member exchange theory emphasized the importance of developing positive relationships between leaders and subordinates (Cooper, Hellriegel \& Slocum, 2017) to create transformation.

\section{Literature Review Viewpoints of Leader and Follower}

\section{The Hierarchy}

Followers have been defined as those who follow others based on their actions or those who are lower in the hierarchy (Kellerman, 2007). A leader has been defined as someone who is higher in the hierarchy in an organization (Kellerman, 2007) or someone who has emerged from the group naturally, been selected by the organization, or been appointed by other group members (Levi, 2017). The way that leaders and followers are defined may carry underlying assumptions. Robert Kelly, professor at the Graduate School of Industrial Administration at Carnegie Mellon University and the author of many books and articles on followership, points out the way we define the roles of followers and leaders clearly influences the interaction between the two (Kelly, 2015). For example, if a leader is defined as responsible for motivating followers, he or she will likely act toward followers as if they need motivation. If we agree that a leader's job is to transform followers, then it must be a follower's job to provide the clay. If followers fail to need transformation, the leader looks ineffective.

\section{Redefining Leadership and Followership}

Kelly (2015) proposes that instead of viewing the leadership role as superior to and more active than the role of follower, leaders should be viewed as equal to followers but with different activities. What distinguishes followership is not a person but a role, and what distinguishes followers from leaders is not intelligence or character but the role they play (Kelly, 2015). In a similar sense, Levi (2017) thinks leadership roles and positions can also be distributed amongst the group members or shared at different points in time. In this paper, I use the redefined followership and leadership to serve as the foundation of our discussion, where they are considered equal roles in status and contribute identical significance in team success.

Cooperation between leaders and followers is essential to the success of the team. Levi (2017) defines team success as a threefold process attributed to task completion, positive relationships among members, and professional and personal goals. The interaction between team members and leaders, also known as the Leadership-Exchange Theory, theorizes that the way which leaders lead will determine how members will react. This interaction between the leader and the "follower" will impact leadership in a continuous cycle. Montano, Reeske, Franke, and Huffmeier (2016) conducted a study on employees and leaders within the mental health field and how the dynamics between powers could affect job performance through the mediating factor of mental health. Montano et. al.'s study (2016) supports the theory that the type of leadership, whether positive or negative, can impact the mental health of employees, which correlates with positive or negative work performance). The research revealed that cooperation can enhance team performance and build supportive relationships (Levi, 2016, p91). From my experience, I found that cooperation between the follower and the leader to create task strategy, boost synchronized communication and problemsolving capabilities through various cognitive and behavioral mechanism strategies to achieve tasks is vital for increased trust and relationship bonding between employees. This is often reflected in organization performance. Although personalities play a significant role in determining cooperation and performance of a team, it also affects the role played within a team, the supervisor and team members' communication style, and the level at which personality core values align with those of the team being considered (Winsborough \& Premuzic, 2017). 


\section{The Follower-Leader Interaction}

Researchers have given significant attention to leadership in the workplace over the past few decades. In recent years, however, there has been blooming research interest in followers within an organization, specifically in the context of the follower-leader interaction. Some research findings suggest that followers' behaviors may have an influence on leadership and its effectiveness in an organization. How leaders and followers interact with one another has shown to be an important component of an organization's success.

Wirtz, Rigotti, Otto, and Loeb (2016) examined emotional exhaustion and work engagement from followers to leaders. Wirtz et. al (2016) used the basis of the leader-member exchange theory that emphasizes the importance of developing positive relationships between leaders and subordinates (Cooper, Hellriegel, \& Slocum, 2017). Wirtz et. al's (2016) research found there was a positive lagged relationship between followers' and leaders' work engagement and over time the level of engagement at work by followers influenced leader engagement. This research finding implicates that follower can shape leaders' work experience, and that valuable contributions come partly from the commitment of the followers' level of engagement in the workplace. Leaders should foster an environment that promotes healthy working relationships and engaging tasks for team members that will help contribute towards the success and good leadership.

Expanding upon the focus of work engagement of Wirtz et al., Aw and Ayoko (2017) examined followers' conflict behaviors, transformational leadership, and the team-member exchange principles. Aw and Ayoko (2017) studied how followers' behavior plays a role in shaping a leader's behavior and leadership style. The team-member exchange quality theory explains the relationships "reciprocity between a member and his or her team with respect to the member's contribution and the receipt of assistance and recognition from other team members" (Seers, Petty, \& Cashman, 1995, p. 512). Seers et. al (1995) hypothesized that different types of conflict behavior, problem-solving, dominating, and non-confronting, would be correlated either positively or negatively to transformational leadership.

Conflict behavior is described as "specific behavioral patterns that individuals prefer to employ in dealing with conflict" (Moberg, 2001, p. 512). An example of problem-solving conflict behavior is having a high concern for self as well as the other party. The findings statistically supported that followers' problem-solving conflict behaviors were positively related to transformational leadership and team-member exchange quality. Previous data on problem-solving behaviors have also has been shown to yield more desirable outcomes for individuals and organizations (Chen, Zhao, Liu, \& Wu, 2012). More desirable outcomes for individuals correlate back to work engagement: if followers are using problem-solving conflict behavior, higher quality of collaborations between team members and level of engagement in the workplace is being employed, which can impact the leader's work engagement and leadership style. Leaders should encourage the use of problem-solving techniques within the team to increase the quality of engagement and followers' relationships. Aw, and Ayoko's (2017) hypothesis linking transformational leadership and team engagement, moderated by team-member exchange quality, was also statistically significant. This further supports the notion good leadership should focus on followers' relationships within the team to enhance team success.

Although leaders play an important role in guiding a team to success, followers' behaviors are partially contributing to how effectively the leader can lead the team. As a leader, understanding how to increase followers' engagement at work and creating meaningful relationships within a team can have a vast influence on the leadership style and team performance within the organization. As a follower, acknowledging that the level of work engagement and behaviors has an impact on the success of the team and the organization is critical to understand and to continue to implement good team and follower practices in the workplace. 


\section{Followers' Potential Value and Contribution in Today's World}

The following section specifically discusses the importance of followers to practice and exhibit critical thinking and mindfulness. When followers use critical thinking and mindfulness, they are able to contribute positively to the team process and problem-solving.

\section{Follower Critical Thinking and Problem Solving}

In problem-solving, the first step is to discuss and document individual views until everyone agrees on the nature of the problem (Pokras, 1995). In practice, identifying the nature of the problem is the most difficult step to happen for teams. Without first understanding the problem, teams often end up with ill-defined problems and underdeveloped criteria for evaluating them. It is crucial for teams to challenge the definitions of the problems, and search for the root cause of problems (Levi, 2017). Followers who exhibit problem-solving skills are crucial to providing organizations with efficient results. It is important to create a culture of resilience to foster the learning attitude and improve problem-solving capabilities (Clark, 2020), in addition to that, it is imperative for the leader to maintain psychological-safe environment to foster organizational learning, resilience, and innovation (Kayes \& Kayes, 2011)

Critical thinking is the thought process that makes people stop, question, and occasionally change once-held beliefs. Every person has the capacity for critical thinking, yet one may not consciously evaluate his or her assumptions of the influence of the surrounding social environment (Merriam \& Bierema, 2012). Assessing the problem critically with a conscientious awareness of the problem-solving process itself increases the likelihood that followers will contribute efficiently. Memduhoglu and Keles (2016) examined the relationship between critical thinking and problemsolving skills of 656 pre-service teachers and found that critical thinking can positively support problem solving. The correlation analysis of Memduhoglu and Keles (2016) indicates that preservice teachers, who are curious, analytical, tolerant, self-confident, and give importance to the truth, do not behave hasty and avoidable while solving problems. It is evident that followers' critical thinking positively supports the team in problem-solving.

\section{Follower Mindfulness and Team Cohesion}

Followers build and contribute to the cohesiveness of a team. While the literature has addressed how leadership can have influence team cohesion, this paper focuses on followers. Followers' mindfulness, the practice of purposely paying attention to the present moment and remaining nonjudgmental contribute to team cohesion (Arif \& Zia-ur-Rehman, 2017).

A number of studies have explored the relationship of mindfulness to emotional intelligence, indicating that there are three specific ways in which this connection is illustrated. First, regular practice of mindfulness meditation may augment one's ability to comprehend self-emotional state so one gets to clearly monitor his/her own emotional state and thus may be also able to manage them well (Creswell, 2007). With the comprehension of one's own emotional state, one is more likely to react positively in a negative state of matters. Similarly, by understanding others' emotional cues, better decisions can be made by leadership (Brown et al., 2007). Third, mindfulness affects one's ability to respond to a given situation more empathetically and effectively (Krasner et al., 2009). Above all, it is believed that mindfulness leads to establishing a culture of relatedness, cooperation, coordination, and collaboration, in the organizational set-up (Bonner et al. 1998).

\section{Research Methodology}

This research "How Followers Contribute to Team Success" aimed to reveal the vital role of followers in making organizational transformation happen and illustrated the qualities of a good followership role to drive a positive change in organizations. It also depicted the role of organizational culture, leadership behaviors, and critical-thinking practices to support followers to thrive. This research used secondary data. The data was analyzed using internal factors such as followership qualities, and external environment factors that influences follower's success in 
organizations such as organization culture, structure, leadership behaviors, and team reward recognition.

\section{Followership Qualities}

\section{Results and Analysis}

Effective followers share many essential qualities that contribute to organizational success: 1 . Effective followers manage themselves well.2. Effective followers are committed to the organization and to a purpose. 3. Effective followers build their competence and focus their efforts for maximum impact. 4. Effective followers are courageous and credible. 5. Effective followers give a cost advantage to organizations. (Kelley, 2015). Followership is present in all areas of our lives despite the formal leadership level that followers occupy. Leaders who play as followers view followership as legitimate, inherently valuable, and virtuous.

To improve the followership role in organizations, it is critical to understand the follower qualities to motivate them. Motivating factors are derived from ambition, and acceptance of the value of learning, and resilience throughout the process.

To measure followership effectiveness. Its critical to consider behavior elements such as critical thinking, independence, enthusiasm, and assertiveness. Effective followers can excel without instructions by taking risks, thinking independently, and solving problems. This will reflect on the effectiveness of team leadership and organization performance overall. The role of the follower is becoming more important as organizational structures tend to be boundless over time. Based on our understanding of followership, Kelley's (2015).

\section{In Praise of Followers}

Despite the vital role leaders play in organizations, great followership is crucial in the operational process. For example, in 1987 when one of the banks on the east coast experienced declining profits, accordingly, leadership started cutting off work and labor. Different leadership approaches were taken by followers to limit time and cost spent during crises, such as delegation of authority to trained staff to manage tasks during leadership absence, setting boundless organization structure, that delegates team members to work on various areas together including operations, and finance. In addition to providing support virtually to direct their efforts toward organization initiatives, and exercise self-management traits to follow effectively in critical moments their organization faced (Kelley, 1988).

\section{Suggestions to Cultivate Effective Followers}

\section{Convey the Meaning of Followership}

The new perspective of leadership and followership can be conveyed to employees directly and indirectly. The qualities that make good followers and the value the company places on effective followership can be articulated in explicit follower training.

The best way to convey the message is by example. Since each of us plays a follower's part at least from time to time, it is essential that we play it well, that we contribute our competence to the achievement of team goals, that we support team leaders with condor and self-control, that we do our best to appreciate and enjoy the role of followership to a larger, common cause (Kelly, 2015). In addition, it is found that identifying and engaging the strengths of the followers rather than weaknesses can foster loyalty, affiliation, and connect the dots between the organization and the followers' goals. (Northhouse, 2018)

\section{The Culture Where Followership is Nurtured and Valued}

Not only does leadership take time to develop, so does followership. Where an organization is providing a culture of psychological safe environment, followers are more likely to develop skills to be effective followers, such as improving independence, critical thinking, self-management, assertive communication, building credibility, and acting responsively. In most organization evaluations, a 
section on leadership skills is included. Instead of relating such qualities as self-management, critical thinking, emotionally healthy, and credibility only to the quality of leadership attributes, they can also be related to followership qualities.

\section{Stay savvy by organization design \& reward system}

It takes organizational design to build the value of good followership into the fabric of the organization. In a flat, lean organization, employees are more likely to have opportunities for exercising effective followership. For example, a leaderless group where all members assume equal responsibility for achieving the group goals, or groups where members rotate leadership role, or use project teams where effective followership is vital. In all organizational settings, a relevant rewards system ultimately underlines the importance of followership.

\section{Conclusion}

While followership hasn't received nearly as much scholarly attention as leadership, there has been a surging interest to study the role of the follower and how they contribute to team success. These recent years of research have indicated that the quality of the follower-leadership exchange is the propelling factor of transformational leadership and that the way that followers interact with leaders is an important component to team success. Effective followers are ones who manage themselves well and are committed to the organization. They are courageous, honest, and continuously strive to improve their level of competence. By Embodying these ideals and behaviors, followers can directly impact of the success of their leaders and teams.

\section{References}

Arif, H. \& Zia-ur-Rehman, M. (2017). How ethical leadership and follower mindfulness play their role in developing organizational commitment. Analyzing the augmentative contribution of emotional capital. Global Management Journal for Academic \& Corporate Studies, 7(1): 7184.

Aw, V. K. J. \& Ayoko, O. B. (2017). The impact of followers' conflict behaviors on teams' transformational leadership, team member exchange and engagement, International Journal of Conflict Management, 8(4), 509-532.

Kelleman, B, (2007), What Every Leader Need to Know About Follower, Harvard Business Review, https://hbr.org/2007/12/what-every-leader-needs-to-know-about-followers (accessed October, 23, 2021)

Brown, K. W., Ryan, R. M., \& Creswell, J. D. (2007). Mindfulness: Theoretical Foundations and Evidence for Its Salutary Effects. Psychological Inquiry, 18(4), 211-237

Chen, X. H., Zhao, K., Liu, X. \& Wu, D. D. (2012). Improving employees' job satisfaction and innovation performance using conflict management. International Journal of Conflict Management, 23(2), 155-172.

Clark, T. (2020). To Foster Innovation, Cultivate a Culture of Intellectual Bravery. Harvard Business Review https://hbr.org/2020/10/to-foster-innovation-cultivate-a-culture-of-intellectualbravery (accessed October 23,2021)

Cooper, C. D., Hellriegel, D. \& Slocum, J. (2017). Leadership effectiveness: Foundations (Chapter 10). Mastering Organizational Behavior (14"ed). (pp.283-308). St. Paul, MN: Southwestern College Publishing

Creswell, J. D., Way, B. M., Eisenberger, N. I., \& Lieberman, M. D. (2007). Neural correlates of dispositional mindfulness during affect labeling. Psychosomatic Medicine, 69(6), 560-565.

DeRue, D. S. (2011). Adaptive leadership theory: leading and following as a complex adaptive process. Research in Organizational Behavior, 31, 125-150.

Kayes, A. B., \& Kayes, C. D. (2011). Learning advantage: Six practices of learning -directed leadership. Palgrave Macmillan Limited.

Levi, D. (2017). Chapter 11: Problem Solving. Group dynamics for teams (5th ed). 
Memduhoglu, H. B. \& Keles, E. (2016) Evaluation of the Relation between Critical-Thinking Tendency and Problem-Solving Skills of Pre-Service Teachers. Journal of Educational Sciences Research, 6(2)

Merriam, S. B. \& Bierema, L. L. (2012). Chapter 11: Critical Thinking and Critical Perspectives. Adult learning linking theory and practice, 212-237.

Moberg, P. J. (2001), Linking conflict strategy to the five-factor model: theoretical and empirical foundations, International Journal of Conflict Management, 12(1), 47-68.

Niam, S (2018). A Behavioral Approach to Understanding Leadership Effectiveness. https://dash.harvard.edu/handle/1/37364556

Northouse, P. (2018), Introduction to Leadership, Concepts and Practice (4th^ed)

Pokras, S. (1995). Team problem solving. Menlo Park, CA: CRISP.

Robert, Kelley, (1988), In Praise of Followers, Harvard Business Review https://hbr.org/1988/11/inpraise-of-followers (accessed October 24,2021)

Seers, A., Petty, M. M. and Cashman, J.F. (1995), Team-member exchange under team and traditional management: a naturally occurring quasi-experiment, Group \& Organization Management. 20(1), 18-38.

Wirtz, N., Rigotti, T., Otto, K., \& Loeb, C. (2017). What about the leader? Crossover of emotional exhaustion and work engagement from followers to leaders. Journal of Occupational Health Psychology, 22(1), 86-97.

Winsborough, D. \& Premuzic, T. (2017). Great Teams Are About Personalities, Not Just Skills. Harvard Business Review. Retrieved From https://hbr.org/2017/01/great-teams-are-aboutpersonalities-not-just-skills (accessed October 24, 2021) 